\title{
Prostatic Artery Embolization for Benign Prostatic Hyperplasia: Anatomical Aspects and Radiation Considerations from a Case Series of 210 Patients
}

\author{
${ }^{1}$ Department of Diagnostic and Interventional Radiology, Ain Shams \\ University, Cairo, Egypt \\ ${ }^{2}$ Department of Department of Diagnostic and Interventional \\ Radiology, Ain Shams University, King's College Hospital, Cairo, \\ Egypt \\ ${ }^{3}$ National Center for Radiation Research and Technology, \\ Cairo, Egypt
}

Mohamed Shaker ${ }^{1} \quad$ Essam Hashem ${ }^{2}$ Ahmed Abdelrahman ${ }^{3} \quad$ Ahmed Okba ${ }^{1}$

Arab J Intervent Radiol 2021;5:3-10.

Address for correspondence Mohamed Shaker, MD, 13 Mostafa Refaat, Sheraton Al Matar, El Nozha, Cairo Governorate 11799, Egypt (e-mail: mohamed_ghazy@med.asu.edu.eg).

\author{
Abstract \\ Keywords \\ - prostate \\ - embolization \\ - prostatic artery \\ embolization \\ - angiographic anatomy \\ - radiation \\ - fluoroscopy time \\ - prostatic anastomosis \\ - nontarget \\ embolization \\ - cone-beam CT
}

Context Prostatic artery embolization (PAE) has been established as a safe and effective treatment option for symptomatic benign prostatic hyperplasia (BPH). Thorough knowledge of detailed prostatic artery (PA) anatomy is essential.

Aims The aim of this study was to provide a pictorial review of PA anatomy and prevalence of related anatomical variants, in addition to other anatomical and radiation dose considerations.

Settings and Design Case series and review of literature.

Materials and Methods We performed PAE for 210 patients from November 2015 to November 2020 under local anesthesia only. Anatomy, procedure duration, fluoroscopy time, radiation dose, technical success, and complications were analyzed.

Statistical Analysis Used Descriptive statistics were analyzed using Microsoft Excel software.

Results A total of 210 patients (420 sides) were analyzed. Double arterial supply on the same side was noted in 12 patients (5.7\%). In 10 patients (4.7\%), only a unilateral PA was identified. In two patients (0.9\%), no PA could be identified. Frequencies of PA origins were calculated. Penile, rectal, and vesical anastomoses were identified with 79 (18.8\%), 54 (12.9\%), and 41 (9.8\%) of PAs, respectively. Median skin radiation dose, procedure time, and fluoroscopy time were $505 \mathrm{mGy}, 73$ and 38 minutes, respectively. Complications occurred in nine patients (4.3\%), none of them was major.

Conclusions Knowledge of PA anatomy is essential when treating BPH by PAE for optimum results. There is no enough evidence to support routine use of preoperative computed tomography angiography and intraoperative cone-beam computed tomography as means of improving safety or efficacy. published online June 22, 2021
DOI https://doi.org/

$10.1055 / \mathrm{s}-0041-1729134$ ISSN 2542-7075 (c) 2021. The Pan Arab Interventional Radiology Society

This is an open access article published by Thieme under the terms of the Creative Commons Attribution-NonDerivative-NonCommercial-License, permitting copying and reproduction so long as the original work is given appropriate credit. Contents may not be used for commercial purposes, or adapted, remixed, transformed or built upon. (https://creativecommons.org/licenses/by-nc-nd/4.0/). Thieme Medical and Scientific Publishers Private Ltd. A-12, Second Floor, Sector -2, NOIDA -201301, India 


\section{Introduction}

PAE has been established as a safe and effective minimally invasive treatment option for moderate and severe lower urinary tract symptoms (LUTS) due to benign prostatic hyperplasia (BPH). ${ }^{1}$

Compared with standard urological interventions, PAE is performed as an outpatient day-case procedure, ${ }^{1}$ suitable for large prostates, ${ }^{2,3}$ suitable for patients with acute urinary retention, ${ }^{4}$ and has a lower overall cost. ${ }^{5}$ PAE has significantly lower risk of severe adverse events compared with standard urological interventions. ${ }^{6-10}$

PAE is often a challenging procedure requiring certain level of knowledge of the arterial anatomy and set of skills, due to varying degrees of atherosclerosis commonly encountered in this age group. ${ }^{11}$ We aim to highlight important anatomical data related to PA that are essential for successful PAE as well as radiation exposure considerations, which can be beneficial in such a relatively lengthy procedure.

\section{Subjects and Methods}

This retrospective study is based on the angiograms of 210 male patients, who underwent PAE between November 2015 and November 2020, to treat obstructive LUTS due to $\mathrm{BPH}$ in patients above the age of 40 with prostate volume more than $40 \mathrm{~mL}$ showing no satisfactory response to medical treatment for at least 6 months. Patients with prostate cancer, impaired renal functions, urinary bladder stones, chronic retention, active urinary tract infection, active prostatitis, or uncorrectable coagulopathy were excluded.

Preprocedural evaluation included history taking, clinical examination, International Prostate Symptom Score (IPSS) and quality of life (QOL) score, maximum urine flow velocity measurement by urine flowmetry that was done in some cases to be sure of the obstructive nature of the patient complain, ultrasonographic examination to evaluate the size of the prostate and postvoiding residual urine volume as well as laboratory investigation panel that included prostate-specific antigen (PSA) with free/total PSA ratio, urine analysis, complete blood picture, bleeding profile, and kidney function tests. Transrectal prostatic biopsy was done for patients with suspiciously high PSA levels. Preoperative investigations did not include angiographic study (e.g., CT or magnetic resonance angiography). Cases included in this study were performed on Philips BV Pulsera machine (Philips Healthcare, Andover, MA, United States). Intraoperative CBCT was not used.

Informed consent was obtained. All procedures were performed as day cases under local anesthesia via the right common femoral access. An initial diagnostic internal iliac angiogram was performed using digital subtraction angiography (DSA) by a 5-French Cobra-2 catheter (Boston Scientific, Marlborough, MA, United States) starting by the left side followed by the right side; images were acquired in an ipsilateral anterior oblique of 30 to 50 degrees and a cranial angulation of 10 to 15 degree to determine the origin and number of Pas, followed by selective catheterization of identified PAs using a 2.4 or 2.7 French microcatheter (Progreat, Terumo, Tokyo, Japan). PA angiogram was performed at anteroposterior, oblique, and sometimes lateral views to detect any extra-prostatic supply or anastomosis. CBCT and preoperative CT angiography (CTA) were not utilized, and we depended upon the angiographic anatomy with different projections to avoid nontarget embolization.

Posterior divisions of internal iliac arteries (IIA) and external iliac arteries were only catheterized if additional supply was suspected (e.g., incomplete prostate blush) or PAs could not be identified from the anterior divisions. Embolization was achieved using 300 to $500 \mu \mathrm{m}$ Embosphere particles (Merit Medical Systems Inc., South Jordan, UT, USA) mixed with contrast and diluted 1:1. The procedure was considered technically successful if at least one PA could be embolized to stasis.

Postprocedural hemostasis was achieved by manual compression of the femoral artery and patients were discharged on the same day after 4 to 6 hours from achieving hemostasis. Discharge medications included antibiotic prophylaxis, nonsteroidal anti-inflammatory medications, and analgesics for 7 to 10 days to control the postembolization symptoms. All patients were evaluated at the clinic 2 to 3 weeks after PAE for the presence of complications and initial response to therapy. Further follow-up at the clinic was performed at 3 and 6 months by ultrasound examination, IPSS, and QOL scores.

Our anatomical review is based upon a simple yet informative classification proposed by Dr Carnevale's group. ${ }^{11}$

Anatomy, procedure duration (PD), radiation dose, fluoroscopy time (FT), technical success, and complications were analyzed. Descriptive statistics were analyzed using Microsoft Excel software.

\section{Results}

The mean age was 63 years (range: 48-90). Images of the 210 patients ( 420 sides) were analyzed by the operators (who are also the authors). A total of 418 PAs were angiographically identified. Double arterial supply on the same side was noted in 12 patients (5.7\%). All duplicates were observed on the left side except one; internal pudendal artery (IPA) and superior vesical artery (SVA) in six patients; IPA and obturator artery $(\mathrm{OA})$ in 4 patients; two separate arteries arising from the IPA in one patient and two separate arteries arising directly from the right anterior division IIA in another patient ( - Fig. 1 ). In 10 patients (4.7\%), only a unilateral PA

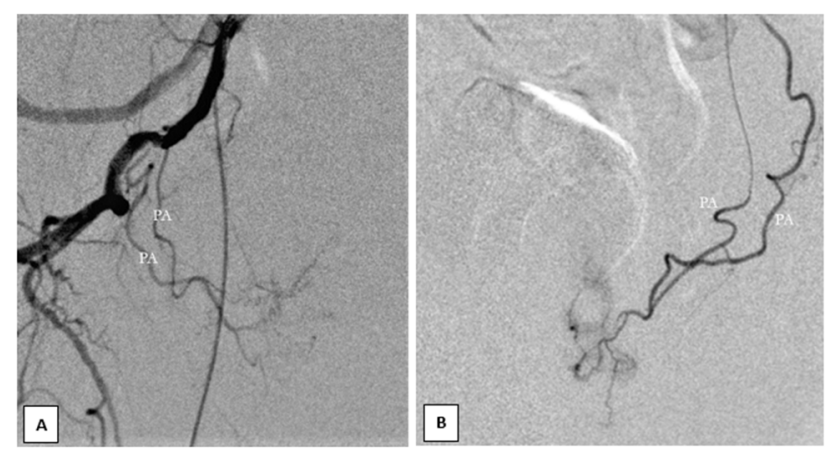

Fig. 1 (A) Right internal iliac angiogram showing Duplicated prostatic artery (PA) arising from the anterior division of internal iliac artery. (B) Selective left prostatic artery angiogram showing retrograde filling of a duplicated prostatic artery. 
was identified despite thorough search in both internal and external iliac branches; this was due to severe atherosclerotic occlusion; in only two patients $(0.9 \%)$ no PA could be identified on either side due to severe aortoiliac occlusive disease. Technical success was defined as successful embolization of at least one PA; this was achieved in 208 cases (99\%). Bilateral embolization was successfully achieved in 189 cases (90\%). Frequencies of PA origins were 167 (39.9\%) from SVA (type I), 122 (29.2\%) from IPA (type IV), 79 (19\%) from OA (type III), 46 (11\%) originated directly from anterior division of IIA (type II), and only $4(0.9 \%)$ originated from elsewhere (type V). The unusual origins were one from external iliac, one from superior gluteal artery, and two from inferior gluteal arteries; in the two latter cases, the inferior gluteal arteries were arising separately early from the anterior division rather than being its continuation. - Figs. 2-6 show several angiographic
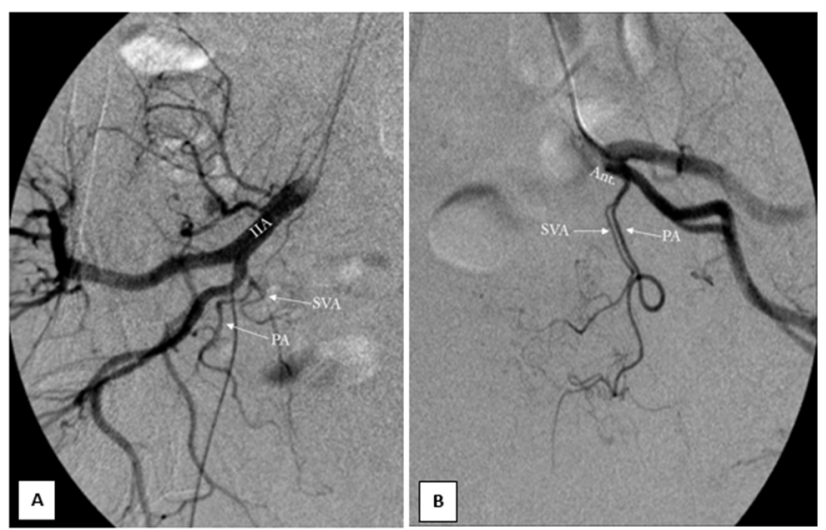

Fig. 2 (A) Right internal iliac artery (IIA) DSA showing type I origin of the prostatic artery (PA) arising with the superior vesical artery (SVA) by a common trunk from the anterior division of the internal iliac artery. (B) Left internal iliac artery DSA showing type I origin of the prostatic artery (PA) arising with the superior vesical artery (SVA) by a common trunk from the anterior division of the internal iliac artery (Ant.).

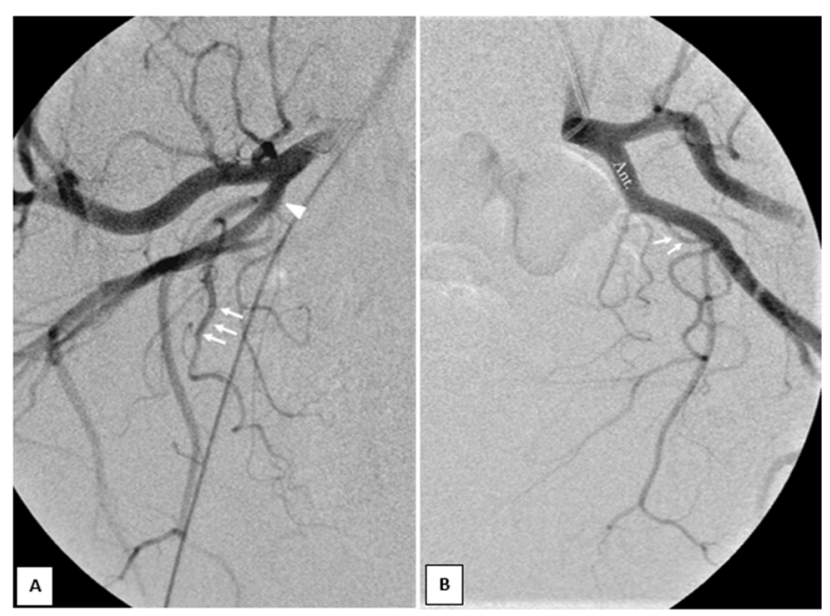

Fig. 3 (A) Right internal iliac artery DSA showing Type II origin of the prostatic artery (arrows) arising by a separate origin from the anterior division of the internal iliac artery (arrowhead). (B) Left internal iliac artery DSA showing Type II origin of the prostatic artery (arrows) arising by a separate origin from the anterior division of the internal iliac artery (Ant.). images of each anatomical type according to Carnevale's classification. ${ }^{11}$ Bilaterally symmetrical PA origins were found in 99 patients (47\%). Out of these 99 patients with symmetrical origins, 43 (43.4\%) originated from SVA, 28 (28.3\%) from IPA, 17 (17.2\%) from OA, and 11 (11.1\%) directly from the anterior division.

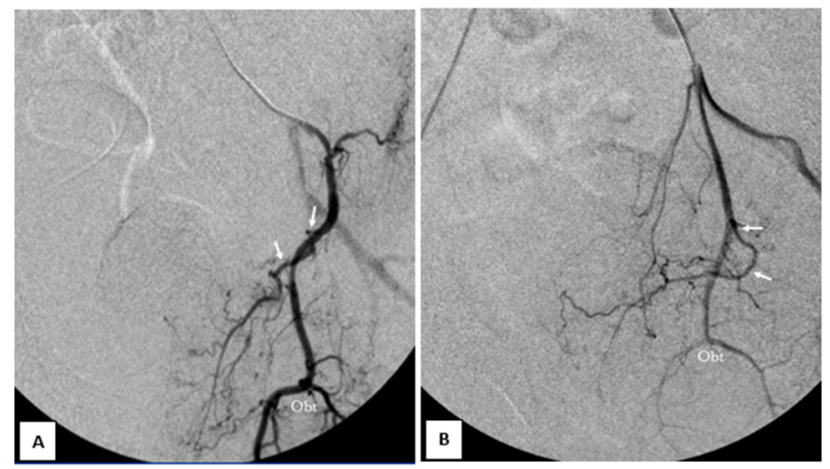

Fig. 4 (A) Selective Left obturator angiogram showing Type III origin of the prostatic artery (arrows) arising from the upper third of the obturator artery (Obt). (B) Selective Left obturator angiogram showing Type III origin of the prostatic artery (arrows) arising from the middle third of the obturator artery (Obt).

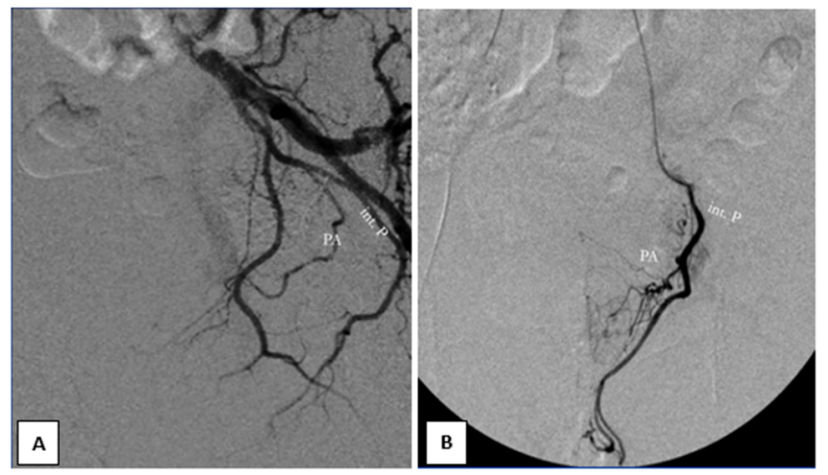

Fig. 5 (A) Left internal iliac angiogram showing Type IV origin of the prostatic artery (PA) arising from the internal pudendal artery (int. P). (B) Selective internal pudendal angiogram showing Type IV origin of the prostatic artery (PA) arising from the internal pudendal artery (int. P).

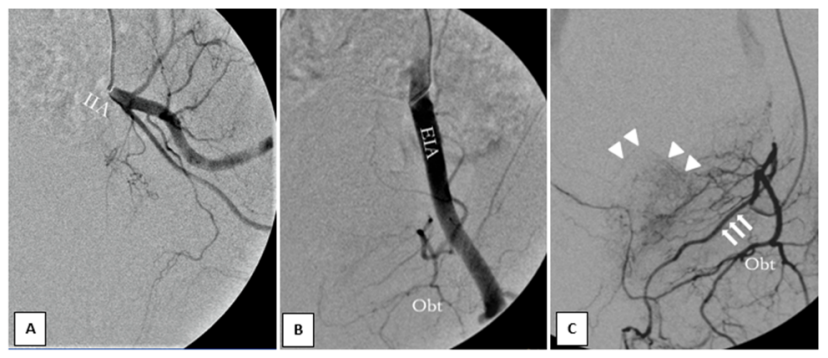

Fig. 6 Left hemipelvic angiogram for the same patient shows type $\checkmark$ origin of prostatic artery arising from external iliac artery (EIA): (A) Left internal iliac artery (IIA) angiogram revealed absent obturator (Obt) and prostatic arteries; (B) left external iliac artery (EIA) gives rise to the obturator artery; (C) selective angiogram of the obturator artery demonstrating prostatic artery supplying prostatic blush (arrowhead), note accessory pudendal (arrows) artery arising from the left prostatic artery. 
Penile, rectal, and vesical anastomoses were angiographically identified with 79 (18.8\%), 54 (12.9\%), and 41 (9.8\%) of PAs, respectively. -Figs. 7-9 show examples of these anastomoses. Accessory pudendal supply arising from PA is also a potential channel for nontarget embolization; this was encountered with 37 PAs (8.8\%) (-Fig. 10). In order of decreasing frequency, the utilized protective techniques to overcome the anastomoses were very slow injection of particles, intraprostatic vasodilators (glyceryl trinitrate $200 \mu \mathrm{g}$ ), coils, and Gelfoam. Protective Gelfoam or coil embolization for nontarget anastomoses was used in 10 cases (4.7\%). Gelfoam (thin slurry) was used in 2 of the 10 cases; both were vesical anastomoses with no enough landing vessel length or diameter to accommodate the smallest available coil in our inventory $(2 \mathrm{~mm})$. Anastomosis between both hemiprostates was detected in 38 patients (18\%), manifesting as filling of contralateral PA branches (-Fig. 11). In two cases, the anastomosis was extensive enough to allow full embolization of the entire gland from one artery only. ${ }^{12}$

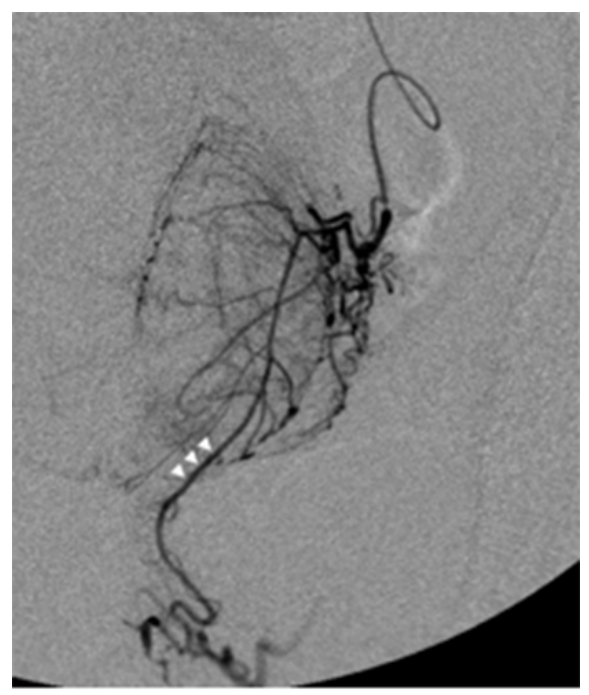

Fig. 7 Selective left prostatic artery angiogram showing intra-prostatic pudendal anastomosis (arrowheads).
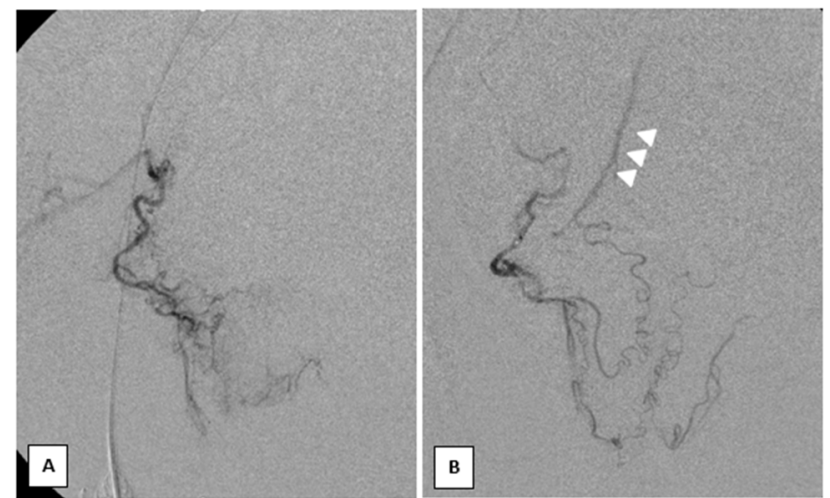

Fig. 8 (A) Selective right prostatic artery angiogram revealing prostatic blush with no angiographically visible anastomosis (B) Intermittent angiography during embolization revealed opening of the rectal anastomosis with retrograde filling of the superior rectal artery (arrowheads) through anastomosis.

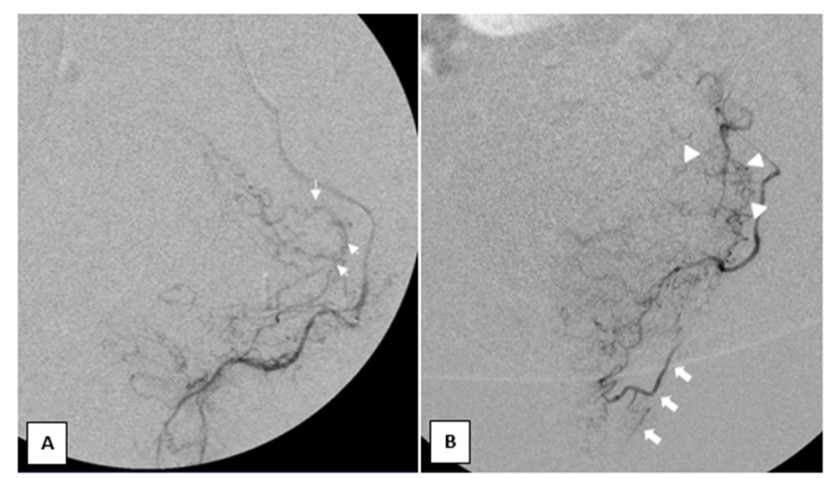

Fig. 9 (A) selective left prostatic artery angiogram reveals vesical anastomosis (arrows). (B) Selective left prostatic artery angiogram revealed rectal (arrows) and vesical (arrowheads) anastomoses

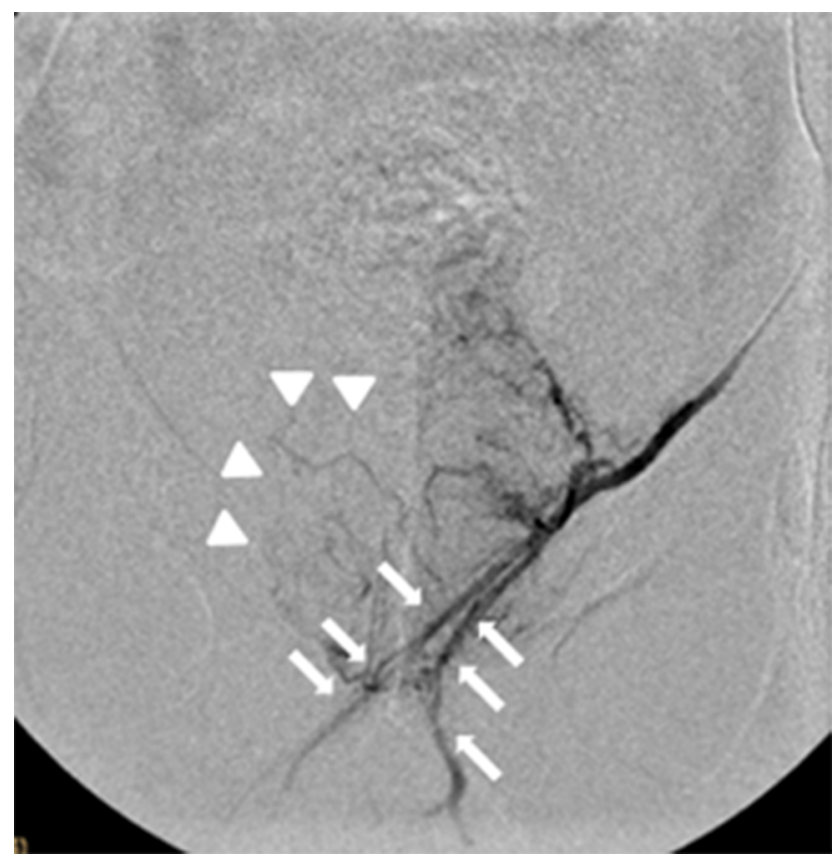

Fig. 10 Selective prostatic artery angiogram revealed accessory pudendal artery (arrows), notice the appearance of right hemiprostate blush through intra-prostatic anastomosis (arrowheads).

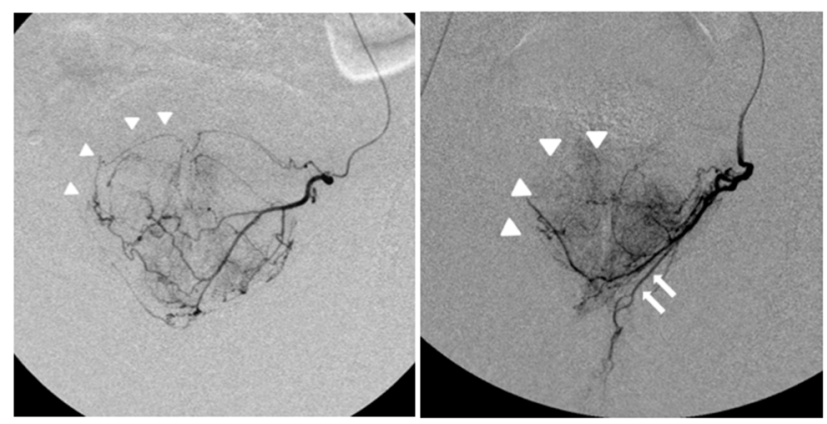

Fig. 11 selective left prostatic artery angiogram for 2 different patients reveals retrograde filling of the contralateral prostatic artery (arrowheads) through intra-prostatic anastomosis. Notice the accessory pudendal artery (Arrows) arising from the left prostatic artery.

Median skin radiation dose, total procedure time, and FT were $505 \mathrm{mGy}, 73$ and 38 minutes, respectively. 
- Table 1 provides detailed data in this regard. Mean prostate volume, median prostate volume, and range were 125,115 , and 45 to $350 \mathrm{~mL}$, respectively. Postembolization syndrome was dealt with as a normal sequel rather than a complication, as it was encountered in almost all patients with varying degrees and it subsided in all patients within 1 to 2 weeks of conservative management (analgesic, anti-inflammatory, and prophylactic antibiotic).

Nine patients experienced minor adverse events (4.3\%): four cases of hematospermia (all subsided within 4 weeks without specific treatment), one case of acute severe pelvic pain on the same night of the operation (successfully treated by intravenous [IV] analgesics on outpatient basis), one case of chronic mild pelvic floor pain that persisted for 3 months, and three cases of urinary tract infection (treated by antibiotic therapy). We encountered no severe adverse events according to standardized incidence ratio (SIR) classification. ${ }^{13}$ We did not encounter any cases of hematuria, hematochezia, or genital ulcers.

\section{Discussion}

This study highlights detailed anatomy of the PA and its variants. ${ }^{11}$ Almost half of the cases had symmetrical origin of PA; this fact should be exploited to spare PD, radiation, and contrast use when searching for the contralateral PA. If the origin is not readily obvious on DSA, one should start by exploring SVA and IPA, because collectively they contribute to about two-thirds of PA origins. Pisco group reported that IPA is the most common origin of PA (35\%) followed by SVA (20\%). ${ }^{14}$ Carnevale group reported IPA and SVA origins to be 31.1 and $28.7 \%$, respectively. ${ }^{15}$ On the other hand, the most common origin in our series was SVA followed by IPA. This agrees with American and German groups reporting that SVA origin as the most common at 35 and $27.5 \%$, respectively. ${ }^{16,17}$

In our series, anastomoses connecting both hemi-prostates were detected in $18 \%$ of cases. The anastomosis was extensive enough to allow complete prostatic embolization through unilateral approach in two cases $(0.9 \%)$, one of them was previously published as a case report. ${ }^{12}$ Extensive anastomosis is reported to be $3 \%$ in the literature. ${ }^{18}$ This is extremely useful in cases where prostate supply is identified/accessible on one side only. The true extent of anastomosis may be best detected using the PERFECTED technique described by Carnevale group. ${ }^{19}$

Protective coils/Gelfoam are extremely useful tools in selected cases, enabling safe embolization of the target arteries. Although coils are most commonly used, Gelfoam use has also been reported in the literature. ${ }^{20}$ If anastomosis is inaccessible, it is recommended to use intraprostatic vasodilators combined with very slow injection of particles. ${ }^{21}$ After such maneuvers, the anastomoses are usually no longer visualized; however, they become more evident when the peripheral resistance increases, after saturation of prostatic vascular bed by particles. Therefore, repeated slow angiograms during the embolization process are important for early detection of saturation, leading to reappearance of flow through the anastomoses into nontarget territory ( - Fig. 8 highlights this concept). UK-ROPE study reported a much higher prevalence of extra-prostatic anastomosis, requiring protective coiling in $25.7 \%$. We assume this was due to the power pump injector used during $\mathrm{CBCT}$ acquisition (instead of the gentle hand injections that we performed) that might have overestimated relevant anastomosis. Another possible explanation for higher sensitivity of anastomosis detection is their CBCT use. Although they reported mean FT shorter than ours (40.6 vs. 44 minute); complications, PD, skin dose, and percentage of bilateral PAE were all in favor of our series (-Table 2). Other studies reported protective embolization rates ranging from 4.3 to $26.2 \% .^{22,23}$

Scrutiny is essential when searching for possible additional prostatic feeders. In our series, we encountered multiplicity of supply (>2 PAs) in $5.7 \%$ of cases. Multiplicity was most encountered as double supply on the left side, which may be because this side is almost always embolized first, with the prostatic bed still well-vascularized, unsaturated with particles yet and with low resistance to blood flow. In the literature, multiplicity of prostatic supply has been described in up to $8.7 \%$ of cases. ${ }^{16}$ Such situation can be misleading due to "satisfaction of search," leading to suboptimal embolization if one or more of these multiple feeders is missed, which may reduce clinical improvement and increase recurrence due to revascularization. ${ }^{24}$

Several PAE series used preoperative CTA for patient selection and procedure planning. Sensitivity of CTA for detection of extra-prostatic anastomosis was found to be $57.5 \%$ only. ${ }^{25}$ We did not use CTA because there is no enough evidence to support routine use for the extra IV contrast, radiation, and cost. In our 210 patients, only two cases $(<1 \%)$ would have been excluded by CTA due to severe aortoiliac occlusive disease. This is not enough to justify the routine use of preoperative CTA for every case. There is insufficient data regarding the proportion of patients excluded from getting PAE based on preoperative CTA findings. This needs further investigation to determine its cost-benefit as a routine investigation for patient selection.

Several studies reported FT, PD and radiation higher than our series. - Table 2 summarizes these findings, in addition

Table 1 Summary of radiation dose, fluoroscopy time, and procedure duration (from groin puncture to last control angiogram)

\begin{tabular}{|l|l|l|l|}
\hline & Skin radiation dose (mGy) & Total procedure time (min) & Fluoroscopy time (min) \\
\hline Median & 505 & 73 & 38 \\
\hline Mean & 578 & 77 & 44 \\
\hline Minimum & 186 & 34 & 18 \\
\hline Maximum & 1570 & 192 & 129 \\
\hline
\end{tabular}


Table 2 Preoperative CTA, intraoperative CBCT, FT, PD, DAP, skin dose, bilateral PAE, and serious complications. Studies are ordered ascendingly according to FT because it is the most consistently reported item. The definition of serious adverse events/ serious complications was variable across studies. Numbers represent mean value unless specified otherwise

\begin{tabular}{|c|c|c|c|c|c|c|c|c|}
\hline Study & CTA & CBCT & FT (min) & PD (min) & $\begin{array}{l}\text { Dose area } \\
\text { product } \\
\left(G y . \mathrm{cm}^{2}\right)\end{array}$ & $\begin{array}{l}\text { Skin dose } \\
\text { (mGy) }\end{array}$ & $\begin{array}{l}\text { Bilateral } \\
\text { PAE }\end{array}$ & $\begin{array}{l}\text { Serious } \\
\text { complications }\end{array}$ \\
\hline Pisco et $\mathrm{al}^{31}$ & Yes & No & 19.5 & 77 & 241.5 & $\mathrm{~N} / \mathrm{A}$ & $\begin{array}{l}98.1 \% \\
(618 / 630)\end{array}$ & $0.3 \%(2 / 630)$ \\
\hline Garzón el al ${ }^{32}$ & No & Yes (2/5) & 29.1 & $\mathrm{~N} / \mathrm{A}$ & 523.9 & 2674.2 & $\mathrm{~N} / \mathrm{A}$ & $\mathrm{N} / \mathrm{A}$ \\
\hline Wang et $\mathrm{a}^{33}$ & Yes & Yes & 30 & 105 & $N / A$ & $N / A$ & $\begin{array}{l}86.3 \% \\
(101 / 117)\end{array}$ & $0 \%(0 / 117)$ \\
\hline Bagla et $a^{28}$ & No & Yes & 30.2 & 72 & 559.2 & $\mathrm{~N} / \mathrm{A}$ & $95 \%(18 / 19)$ & $0 \%(0 / 19)$ \\
\hline Andrade et $a^{26}$ & No & $\begin{array}{l}\text { Yes } \\
(7 / 25)\end{array}$ & 30.9 & $\mathrm{~N} / \mathrm{A}$ & 450.7 & 2420.3 & $\begin{array}{l}100 \% \\
(25 / 25)\end{array}$ & $\mathrm{N} / \mathrm{A}$ \\
\hline Schott et al ${ }^{27}$ & No & Yes & 30.9 & 89.4 & 134 & $\mathrm{~N} / \mathrm{A}$ & $\begin{array}{l}83 \% \\
(83 / 100)\end{array}$ & $\mathrm{N} / \mathrm{A}$ \\
\hline $\begin{array}{l}\text { du Pisanie et al }{ }^{16} \\
\text { operator } 2\end{array}$ & Yes & No & 31 & 72.9 & 59.2 & $\mathrm{~N} / \mathrm{A}$ & $\begin{array}{l}98.5 \% \\
(66 / 67)\end{array}$ & $\mathrm{N} / \mathrm{A}$ \\
\hline Gao et al ${ }^{9}$ & No & No & 33.2 & 89.7 & 113 & $\mathrm{~N} / \mathrm{A}$ & $\begin{array}{l}94.7 \% \\
(54 / 57)\end{array}$ & $1.7 \%(1 / 57)$ \\
\hline Enderlein et al ${ }^{17}$ & No & Yes & 35 & 156 (median) & $\begin{array}{l}432.1 \\
\text { (median) }\end{array}$ & $N / A$ & $\begin{array}{l}94.2 \% \\
(98 / 104)\end{array}$ & $\mathrm{N} / \mathrm{A}$ \\
\hline $\begin{array}{l}\text { du Pisanie et al }{ }^{16} \\
\text { operator } 1\end{array}$ & $\begin{array}{l}\text { Yes } \\
(86 / 150)\end{array}$ & $\begin{array}{l}\text { Yes } \\
(64 / 150)\end{array}$ & 39.1 & 119.3 & 197.5 & $\mathrm{~N} / \mathrm{A}$ & $\begin{array}{l}96.6 \% \\
(145 / 150)\end{array}$ & $\mathrm{N} / \mathrm{A}$ \\
\hline Hacking et $\mathrm{al}^{25}$ & Yes & Yes & 40.6 & 145.2 & 221 & 2072.8 & $\begin{array}{l}88 \% \\
(165 / 187)\end{array}$ & $0.9 \%(2 / 216)$ \\
\hline Our study & No & No & 44 & 77 & $\mathrm{~N} / \mathrm{A}$ & 578 & $\begin{array}{l}90 \% \\
(189 / 210)\end{array}$ & $0 \%(0 / 210)$ \\
\hline Carnevale et $a^{34}$ & No (MRI) & Yes & $45.8-49.2$ & $144.8-147.5$ & $\mathrm{~N} / \mathrm{A}$ & $\mathrm{N} / \mathrm{A}$ & $100 \%$ & $0 \%(0 / 30)$ \\
\hline Chiaradia et al $\left.\right|^{35}$ & No & Yes & 47 & $\mathrm{~N} / \mathrm{A}$ & 454 & $\mathrm{~N} / \mathrm{A}$ & $66.7 \%(4 / 6)$ & $0 \%(0 / 6)$ \\
\hline Abt et $\mathrm{al}^{7}$ & No & Yes & 50.8 & 122.2 & 176.5 & $\mathrm{~N} / \mathrm{A}$ & $75 \%(36 / 48)$ & $4.2 \%(2 / 48)$ \\
\hline Amouyal et al ${ }^{19}$ & No (MRI) & $\begin{array}{l}\text { Yes } \\
(25 / 32)\end{array}$ & 54 & 139 & 364.7 & 3,065 & $97 \%(31 / 32)$ & $0 \%(0 / 32)$ \\
\hline de Assis et $a^{3}$ & No (MRI) & No & 55.4 & 158 & $\mathrm{~N} / \mathrm{A}$ & $\mathrm{N} / \mathrm{A}$ & $\begin{array}{l}94.3 \% \\
(33 / 35)\end{array}$ & $2.9 \%(1 / 35)$ \\
\hline Grosso et al ${ }^{36}$ & Yes & No & 69 & 165 & $\mathrm{~N} / \mathrm{A}$ & $\mathrm{N} / \mathrm{A}$ & $69.2 \%(9 / 13)$ & $0 \%(0 / 13)$ \\
\hline
\end{tabular}

Abbreviations: CBCT, cone-beam computed tomography; CTA, computed tomography; DAP, dose-area product; FT, fluoroscopy time; MRI, magnetic resonance imaging; N/A, not available; PAE, prostatic artery embolization; PD, procedure duration.

to other technical and clinical parameters. Some studies reported FTs comparable to ours; however, PDs were significantly longer. This can be attributed to the arrangements required to perform intraoperative $\mathrm{CBCT}$ (e.g., repositioning the patient/table, preparing the injector, resuming the procedure with a new run).

In a prospective single-operator study specifically investigating radiation exposure during PAE, CBCT contributed to $\sim 9 \%$ of the total dose-area product. FT from the same study was not significantly reduced to justify the extra-radiation exposure. Moreover, the study did not report the total PD. ${ }^{26}$ Performing CBCT requires arrangements that may prolong total $\mathrm{PD}$. Another study specifically investigating the utility of $\mathrm{CBCT}$ reported PD longer than ours. Moreover, bilateral embolization was performed in $83 \%$ of cases only. They reported reasons for unsuccessful embolization were as follows: severe arteriosclerosis/stenosis ( 8 patients had unilateral PA stenosis and 1 patient had bilateral stenosis), nontarget anastomoses inaccessible by coil embolization (3 patients), vasospasms of PA (2 patients), and inability to identify a PA (3 patients). Interestingly, the study did not comment on postprocedure complications. ${ }^{27}$ Several other studies that utilized $\mathrm{CBCT}$ did not comment on adverse events either (-Table 2). Bagla et al reported $16 \%$ hematospermia despite utilizing CBCT. ${ }^{28}$

Throughout literature, routine use of preoperative CTA and intraoperative $\mathrm{CBCT}$ did not consistently reduce $\mathrm{FT}$, PD, radiation dose or increase bilateral embolization rate. ${ }^{25,29}$ Studies that did not use CTA/CBCT did not report significantly higher complication rates. In our series, there was a low complication rate, and we did not encounter any serious adverse events. There are scarce comparative data highlighting any statistically significant benefit of CBCT, in terms of the previously mentioned parameters. ${ }^{30}$ This area needs more 
comparative data, preferably randomized controlled trials. Finally, a recent large American study found no significant difference between CTA and CBCT regarding FT, PD, radiation dose, or contrast volume. ${ }^{16}$ - Table 2 summarizes and compares data from literature regarding technical, radiation, and clinical outcomes (including our study).

\section{Limitations of the Study}

Our study has no intraoperative CBCT control group.

\section{Conclusion}

Detailed knowledge of PA anatomy is essential for treating $\mathrm{BPH}$ by PAE to enhance technical success, reduce complications due to nontarget embolization, shorten the procedure, and reduce radiation exposure. There is no enough evidence to support routine use of preoperative CTA and intraoperative CBCT as means of improving safety or efficacy. Randomized controlled studies are required in this regard.

\section{Conflict of Interest}

None.

\section{References}

1 McWilliams JP, Bilhim TA, Carnevale FC, et al. Society of Interventional Radiology Multisociety Consensus Position Statement on Prostatic Artery Embolization for Treatment of Lower Urinary Tract Symptoms Attributed to Benign Prostatic Hyperplasia: From the Society of Interventional Radiology, the Cardiovascular and Interventional Radiological Society of Europe, Société Française de Radiologie, and the British Society of Interventional Radiology: Endorsed by the Asia Pacific Society of Cardiovascular and Interventional Radiology, Canadian Association for Interventional Radiology, Chinese College of Interventionalists, Interventional Radiology Society of Australasia, Japanese Society of Interventional Radiology, and Korean Society of Interventional Radiology. J Vasc Interv Radiol 2019;30(5):627-637.e1

2 Bhatia S, Sinha VK, Harward S, Gomez C, Kava BR, Parekh DJ. Prostate artery embolization in patients with prostate volumes of $80 \mathrm{ml}$ or more: a single-institution retrospective experience of 93 patients. J Vasc Interv Radiol 2018;29(10):1392-1398

3 de Assis AM, Moreira AM, de Paula Rodrigues VC, et al. Prostatic artery embolization for treatment of benign prostatic hyperplasia in patients with prostates $>90 \mathrm{~g}$ : a prospective single-center study. J Vasc Interv Radiol 2015;26(1):87-93

4 Bhatia S, Sinha VK, Kava BR, et al. Efficacy of prostatic artery embolization for catheter-dependent patients with large prostate sizes and high comorbidity scores. J Vasc Interv Radiol 2018;29(1):78-84.e1

5 Bagla S, Smirniotopoulos J, Orlando J, Piechowiak R. Cost analysis of prostate artery embolization (PAE) and transurethral resection of the prostate (TURP) in the treatment of benign prostatic hyperplasia. Cardiovasc Intervent Radiol 2017;40(11):1694-1697

6 Russo GI, Kurbatov D, Sansalone S, et al. Prostatic arterial embolization vs open prostatectomy: a 1-year matched-pair analysis of functional outcomes and morbidities. Urology 2015;86(2):343-348
7 Abt D, Hechelhammer L, Müllhaupt G, et al. Comparison of prostatic artery embolisation (PAE) versus transurethral resection of the prostate (TURP) for benign prostatic hyperplasia: randomised, open label, non-inferiority trial. BMJ 2018;361:k233810.1136/bmj.k2338

8 Rassweiler J, Teber D, Kuntz R, Hofmann R. Complications of transurethral resection of the prostate (TURP)-incidence, management, and prevention. Eur Urol 2006;50(5):969-979, discussion 980

9 Gao YA, Huang Y, Zhang R, et al. Benign prostatic hyperplasia: prostatic arterial embolization versus transurethral resection of the prostate-a prospective, randomized, and controlled clinical trial. Radiology 2014;270(3):920-928

10 Hashem E, Elsobky S, Khalifa M. Prostate artery embolization for benign prostate hyperplasia review: patient selection, outcomes, and technique. Semin Ultrasound CT MR 2020; 41(4):357-365

11 Carnevale FC, Soares GR, de Assis AM, Moreira AM, Harward SH, Cerri GG. Anatomical variants in prostate artery embolization: a pictorial essay. Cardiovasc Intervent Radiol 2017;40(9):1321-1337

12 Shaker M, Hashem E. Benign prostatic hyperplasia treated entirely by unilateral prostate artery embolization. Arab J Interv Radiol 2020;4(1):4010.4103/ajir.ajir_22_19

13 Khalilzadeh O, Baerlocher MO, Shyn PB, et al. Proposal of a new adverse event classification by the Society of Interventional Radiology Standards of Practice Committee. J Vasc Interv Radiol 2017;28(10):1432-1437.e3

14 Bilhim T, Tinto HR, Fernandes L. Martins Pisco J. Radiological anatomy of prostatic arteries. Tech Vasc Interv Radiol 2012;15(4):276-285

15 de Assis AM, Moreira AM, de Paula Rodrigues VC, et al. Pelvic arterial anatomy relevant to prostatic artery embolisation and proposal for angiographic classification. Cardiovasc Intervent Radiol 2015;38(4):855-861

16 du Pisanie J, Abumoussa A, Donovan K, Stewart J, Bagla S, Isaacson A. Predictors of prostatic artery embolization technical outcomes: patient and procedural factors. J Vasc Interv Radiol 2019;30(2):233-240

17 Enderlein GF, Lehmann T, von Rundstedt FC, et al. Prostatic artery embolization-anatomic predictors of technical outcomes. J Vasc Interv Radiol 2020;31(3):378-387

18 Amouyal G, Pellerin O, Del Giudice C, Déan C, Thiounn N, Sapoval M. Bilateral arterial embolization of the prostate through a single prostatic artery: a case series. Cardiovasc Intervent Radiol 2017;40(5):780-787

19 Amouyal G, Thiounn N, Pellerin O, et al. Clinical results after prostatic artery embolization using the PErFecTED technique: a single-center study. Cardiovasc Intervent Radiol 2016;39(3):367-375

20 Amouyal G, Chague P, Pellerin O, et al. Safety and efficacy of occlusion of large extra-prostatic anastomoses during prostatic artery embolization for symptomatic BPH. Cardiovasc Intervent Radiol 2016;39(9):1245-1255

21 Yu SCH, Cho C, Hung E, et al. Case-control study of intra-arterial verapamil for intraprostatic anastomoses to extraprostatic arteries in prostatic artery embolization for benign prostatic hypertrophy. J Vasc Interv Radiol 2017;28(8):1167-1176

22 Torres D, Costa NV, Pisco J, Pinheiro LC, Oliveira AG, Bilhim T. Prostatic artery embolization for benign prostatic hyperplasia: prospective randomized trial of $100-300 \mu \mathrm{m}$ versus $300-500$ $\mu \mathrm{m}$ versus $100-$ to $300-\mu \mathrm{m}+300$ - to $500-\mu \mathrm{m}$ Embospheres. J Vasc Interv Radiol 2019;30(5):638-644

23 Bhatia S, Sinha V, Bordegaray M, Kably I, Harward S, Narayanan G. Role of coil embolization during prostatic artery 
embolization: incidence, indications, and safety profile* J Vasc Interv Radiol 2017;28(5):656-664.e3

24 de Assis AM, Moreira AM, Carnevale FC. Angiographic findings during repeat prostatic artery embolization. J Vasc Interv Radiol 2019;30(5):645-651

25 Hacking N, Vigneswaran G, Maclean D, et al. Technical and imaging outcomes from the UK Registry of Prostate Artery Embolization (UK-ROPE) study: focusing on predictors of clinical success. Cardiovasc Intervent Radiol 2019;42(5):666-676

26 Andrade G, Khoury HJ, Garzón WJ, et al. Radiation exposure of patients and interventional radiologists during prostatic artery embolization: a prospective single-operator study. J Vasc Interv Radiol 2017;28(4):517-521

27 Schott P, Katoh M, Fischer N, Freyhardt P. Radiation dose in prostatic artery embolization using cone-beam CT and 3D Roadmap Software. J Vasc Interv Radiol 2019;30(9):1452-1458

28 Bagla S, Martin CP, van Breda A, et al. Early results from a United States trial of prostatic artery embolization in the treatment of benign prostatic hyperplasia. J Vasc Interv Radiol 2014;25(1):47-52

29 Ray AF, Powell J, Speakman MJ, et al. Efficacy and safety of prostate artery embolization for benign prostatic hyperplasia: an observational study and propensity-matched comparison with transurethral resection of the prostate (the UK-ROPE study) BJU Int 2018;122(2):270-282

30 Wang MQ, Duan F, Yuan K, Zhang GD, Yan J, Wang Y. Benign prostatic hyperplasia: cone-beam CT in conjunction with
DSA for identifying prostatic arterial anatomy. Radiology 2017;282(1):271-280

31 Pisco JM, Bilhim T, Pinheiro LC, et al. Medium- and long-term outcome of prostate artery embolization for patients with benign prostatic hyperplasia: results in 630 patients. J Vasc Interv Radiol 2016;27(8):1115-1122

32 Garzón WJ, Andrade G, Dubourcq F, et al. Prostatic artery embolization: radiation exposure to patients and staff. J Radiol Prot 2016;36(2):246-254

33 Wang M, Guo L, Duan F, et al. Prostatic arterial embolization for the treatment of lower urinary tract symptoms caused by benign prostatic hyperplasia: a comparative study of mediumand large-volume prostates. BJU Int 2016;117(1):155-164

34 Carnevale FC, Iscaife A, Yoshinaga EM, Moreira AM, Antunes AA, Srougi M. Transurethral resection of the prostate (TURP) versus original and PErFecTED prostate artery embolization (PAE) due to benign prostatic hyperplasia (BPH): preliminary results of a single center, prospective, urodynamic-controlled analysis. Cardiovasc Intervent Radiol 2016;39(1):44-52

35 Chiaradia M, Radaelli A, Campeggi A. Bouanane M, De La Taille A, Kobeiter H. Automatic three-dimensional detection of prostatic arteries using cone-beam CT during prostatic arterial embolization. J Vasc Interv Radiol 2015;26(3):413-417

36 Grosso M, Balderi A, Arnò M, et al. Prostatic artery embolization in benign prostatic hyperplasia: preliminary results in 13 patients. Radiol Med (Torino) 2015;120(4):361-368 